REVISTA ANDALUZA DE ANTROPOLOGÍA.

NÚMERO 9: LA REPRESENTACIÓN DE LAS CULTURAS EN LA MUSEOLOGÍA ANTROPOLÓGICA DEL ESTADO ESPAÑOL

SEPTIEMBRE DE 2015

ISSN 2174-6796

[pp. 216-221]

http://dx.doi.org/10.12795/RAA.2015.i09.10

\title{
SÁNCHEZ, PURA (2014). Mujeres en Obras. La construcción interminable de la feminidad. Sevilla: Aconcagua Libros, 182 pp.
}

\section{Carmen Mozo \\ Universidad de Sevilla}

El título del último libro de Pura Sánchez, Mujeres en Obras. La construcción interminable de la feminidad, nos remite a un proyecto inacabado, imposible, pero no por ello ni inocuo, ni inocente. El texto analiza cómo las revistas autodenominadas "femeninas", esto es, destinadas a las mujeres, han ido construyendo una imagen normativa de la feminidad, han ido definiendo lo que debe ser una mujer "adecuada", estudiando un periodo histórico que abarca desde el inicio del reinado de Isabel II (1833) hasta la aprobación de la Constitución de 1978.

Examinando con detenimiento pero también con agilidad y destreza las principales publicaciones para mujeres en esos casi 150 años, muestra cómo estas han ido construyendo y reconstruyendo una identidad femenina que singulariza y esencializa a "la" mujer en la medida en que constituye un modelo normativo: lo que la mujer "es" significa, en realidad, lo que la mujer "debe ser". Y destaca en este proceso el papel de los expertos, aquellos que, siguiendo el expresivo título de la obra de Ehrenreich y English [1975] Por tu propio bien. 150 años de consejos expertos a las mujeres, actuaban (y siguen actuando, por cierto) por "el bien de las mujeres" que es, en realidad, el bien del orden social y también el suyo propio, en la medida que se garantizan un campo profesional. 
Pura Sánchez, que en obras anteriores se ha interesado especialmente por la especificidad de la represión que sufrieron las mujeres bajo el franquismo, reincide ahora en su interés por estas últimas y nos incita a debatir sobre el significado, la importancia y la pertinencia de una "historia de las mujeres". Existe un amplio consenso y una agudizada conciencia en los estudios feministas de que el sesgo androcéntrico (Molyneux, 1977) no se erradica añadiendo mujeres a la historia. Considerar que también las mujeres son sujetos sociales; entender que también las relaciones en las que ellas se encuentran inmersas son socialmente significativas; obliga a repensar la lectura canónica sobre la historia, obliga a repensar qué sujetos y qué cuestiones hemos considerado relevantes para explicar la realidad. Y es precisamente a esto a lo que nos conmina Pura Sánchez con sus contribuciones a la historia de las mujeres, que no son, como ella misma aclara, una moda políticamente correcta o económicamente rentable o, dicho en palabras de la historiadora Joan Scott [1985], que no hacen un uso descriptivo del concepto "género" que, equiparándolo a "mujeres", garantiza y acota un campo de investigación científicamente respetable. Por el contrario, el interés de Pura Sánchez por la historia de las mujeres nos revela cómo actúan, y con qué finalidad, las relaciones sociales de sexo definiendo y redefiniendo lo social, en articulación siempre con los ordenamientos económicos y políticos de cada momento. Efectivamente, en la obra, sistema sexo-género y sistema económico, patriarcado y capitalismo, van de la mano. De esta forma, la autora mostrará cómo la construcción de una determinada “identidad femenina”, leída a través de las revistas femeninas, que actúan en colaboración o no con el sistema educativo, es funcional a las distintas coyunturas históricas analizadas. Por ejemplo, comprobaremos cómo durante el franquismo, la abnegación y el espíritu de sacrificio de la mujer "como debe de ser" permitía utilizarla para las necesidades de reconstrucción nacional de la posguerra, en un modelo de participación política que no acababa con la "feminidad" ni rompía el ideal de domesticidad; y cómo ese modelo de mujer "como debe de ser" se transforma en el de la mujer "moderna y perfecta" para adaptarlo a las necesidades del desarrollismo de los años setenta. Cada periodo histórico construye su identidad femenina y, en la obra, las revistas para mujeres se abordan como un especial vehículo de esa construcción.

El libro, sin embargo, no cae en el peligro de simplificar esos discursos, y señala cómo estos estaban atentos a las diferencias de clase de sus destinatarias; ni cae en el peligro de homogeneizar al patriarcado, y presenta asílas diferentes formas que adopta la desigualdad y sus quiebras; ni cae, por último, en el peligro de ofrecer una visión monolítica de la realidad, señalando por el contrario los conflictos, las divergencias, las continuidades y discontinuidades existentes en la misma.

El concepto de historia adoptado expresa un firme compromiso con la utilidad social de la ciencia como instrumento para comprender y potencialmente transformar la realidad. 
El presente y el pasado, plantea la autora, son construcciones intelectuales, formas de pensar la realidad que establecen "lo que fue" en oposición a "lo que es". Lo relevante en relación al tiempo en la historia no es "el pasado" o "el presente" sino el cambio. Introduciéndome en las páginas de Mujeres en Obras recordaba un pequeño texto de la historiadora feminista Amparo Moreno, Pensar la historia a ras de piel (1991), cuando proclama la necesidad de re-pensar la Historia, "porque lo que llamamos pasado no está aquí y ahora ausente, sino que subyace a todo cuanto hacemos y decimos personal y colectivamente" (p.14).

Esa centralidad concedida al cambio, a las rupturas y continuidades, explica que la autora tenga muy presente que los modelos hegemónicos no surgen del consenso sino del conflicto entre propuestas enfrentadas y divergentes. Y que es muy importante analizar la naturaleza de estos debates para devolver su carácter histórico a fenómenos que aparecen naturalizados, eternizados, y por tanto introducir la posibilidad de su transformación. Por ello, a lo largo del texto se analizan tanto los contenidos de la identidad femenina decimonónica que devino hegemónica y sus reelaboraciones como los intentos por superarla o transgredirla. Y ello no por casualidad, sino porque a partir de la Ilustración se construyó una "naturaleza" diferenciada para cada uno de los sexos que asentó los pilares de lo que conocemos como "feminidad", pilares que se hayan firmemente establecidos y que cimentan a la mujer fundamentalmente como esposa y madre, responsable del llamado "ámbito doméstico" o, dicho en palabras de la economía feminista actual, de los trabajos de cuidado y mantenimiento de la vida humana.

Es introduciendo la naturaleza de los debates que acompañan siempre a la imposición de los modelos normativos como podremos, tras un largo proyecto de enajenación, devolver a las mujeres "los instrumentos para pensarse y entender su presente así como para construir su futuro", como reivindica Pura Sánchez; crear las condiciones para que las mujeres se piensen a sí mismas, como intentaron, en opinión de la autora, las revistas feministas publicadas durante la Transición.

En lo que sigue a continuación, voy a sintetizar los aspectos a mi entender más relevantes del contenido de la obra, presentando la estructura de los distintos capítulos que la componen.

El capítulo 1 aborda el reinado de Isabel II. "Educadas e instruidas" analiza los dos tipos de revistas publicadas en la época, los "museos" y "álbumes", dirigidas a la familia y a los niños, y aquellas destinadas específicamente a mujeres. Mujeres carentes que deben ser "educadas" para ejercer su labor como madres, esposas y amas de casa; y mujeres "instruidas", aditamento conveniente como signo de distinción social para las mujeres de la aristocracia y de la burguesía. El Sexenio Revolucionario abordado en el capítulo 2 trae de la mano, entre otros, el término "Ilustradas" a las publicaciones generalistas primero y femeninas algo después, ya en el reinado de Alfonso XII, término que se mantendrá 
desvirtuado en su contenido hasta la primera década del siglo XX. Interesada en las propuestas alternativas, la autora se detiene en los intentos fourieristas de construir una identidad alternativa a la identidad decimonónica analizada en el capítulo anterior. Como señala Campos (1995), la obra de Charles Fourier es la expresión teórica de la posibilidad de una política y de una forma de vida diferentes. No obstante, el socialismo utópico, hijo de su tiempo, no renuncia a la existencia de diferencias naturales entre los sexos. Es así que las fourieristas $\mathrm{M}^{\mathrm{a}}$ José Zapata y Margarita Pérez de Célis inician durante diez años (1856-1866) una actividad editorial con sumas dificultades y oposiciones, en la que transgreden la concepción ilustrada del "ángel del hogar" pero por la vía del humanitarismo y la caridad "característica" de la feminidad concebida como esencia. El espíritu ilustrado que animó la breve I República Española da algunos frutos durante el reinado de Alfonso XII, destacando las publicaciones de Matilde Cherner que, aún sin abandonar del todo los límites impuestos por el pensamiento decimonónico y biologicista, sí supuso un intento de romper con el modelo patriarcal más tradicional.

En la II República aparecieron nuevas publicaciones dirigidas a mujeres en las que la autora detecta rasgos nuevos de la identidad femenina y se pregunta, dando así inicio al capítulo 3, "Modernas y cultas. Cultura general/cultural integral", si estos nuevos rasgos supusieron transformaciones, o no, con respecto al modelo anterior. De entrada, corrobora cómo las innovaciones jurídicas y educativas decretadas por la República establecieron un marco en el que se trató de articular no una "otredad" femenina excluyente sino una identidad ciudadana igualitaria.

En dicho marco, la autora analiza el universo ideológico conservador, aferrado a la mujer como "ángel del hogar" a la que por razones políticas coyunturales se les pide su incorporación a lo público como propagandistas de dicha ideología pero sin alterar por ello el eterno femenino, y lo hace a través de la revista ELLAS. En litigio con ELLAS, CULTURA INTEGRAL FEMENINA es representativa de los movimientos republicanos feministas, que defienden el concepto de modernidad republicana: mujeres conocedoras de sus derechos ciudadanos. "Modernas y cultas" expresa una nueva identidad cuya principal innovación es la importancia concedida a la cultura como instrumento de emancipación, una cultura inclusiva y no excluyente y marcadora de la otredad como la que manejaba ELLAS.

En un espacio intermedio en el que se debatía sobre una modernidad con matices y que creía en la necesidad de un movimiento feminista, Pura Sánchez analiza la revista MUNDO FEMENINO que, sin romper el marco identitario que naturaliza a la mujer como más sensible y especializada en el ámbito familiar, revela la existencia de un importante debate feminista en la época. Impulsa la creación de un Partido Feminista independiente (cuestión que la autora sólo nombra pero no profundiza) y debate en sus páginas temas tales como la igualdad de derechos en el matrimonio. Lo cual expresa la 
especificidad de la llamada "primera ola" del movimiento feminista (Millet, 1969), de clase media y urbana (y heterosexual, añadiríamos) y sus limitaciones. Sin embargo, así como Pura Sánchez resalta los claroscuros de este feminismo, el conocido históricamente como sufragismo, se echa de menos una tarea similar con respecto al feminismo republicano. Las publicaciones de dictadura franquista son analizadas en dos periodos. El capítulo 4 se ocupa de la década de los cuarenta y cincuenta, años de autarquía económica, en los que, frente a las propuestas cerradas y rígidas del régimen, frente a las mujeres sumisas y sujetas al hogar, frente a las mujeres madres, la autora presenta a las chicas "topolino" o las mujeres "vamp" como intentos de contestar el modelo hegemónico aún sin romper con su marco normativo, lo cual da cuenta de la complejidad siempre presente en la realidad social incluso en momentos dictatoriales y de absoluta falta de libertad. Y las revistas femeninas como instrumentos que claman y advierten en contra de esas fisuras e instan a volver al orden socio-sexual.

El proceso modernizador de los años sesenta es analizado en el capítulo 5, donde las revistas para mujeres resignifican la palabra "moderna" vaciándola de los contenidos emancipadores de la II República y, de la mujer “como Dios manda” del capítulo anterior, proponen a la mujer "moderna y perfecta" que adapta el modelo tradicional a los cambios requeridos por el llamado "desarrollismo económico".

En este periodo aparecen en las revistas los test, reflejo de la vulgarización de la psicología. Estos test, que todavía hoy podemos reconocer en tantas publicaciones, le sirven a la autora para constatar el discurso sobre las mujeres, a las que se trata de ignorantes e inadecuadas, enseñándoles a saber si están o no enamoradas, a conocer al amado, a los hijos, a ser la compañera "perfecta”, a ser femeninas, a conocer su "personalidad”...

Finalmente, los dos últimos capítulos se ocupan del periodo de la Transición. En el capítulo 6, "La mujer nueva", se analizan brevemente las revistas publicadas en la segunda mitad de los años setenta, caracterizadas por la desorientación sobre el modelo a prescribir en los inicios de la democracia, que coexisten con otros proyectos editoriales alternativos, revisados en el capítulo 7, titulado "Emancipadas y liberadas", destinados a construir una conciencia feminista y que ilustran un uso diferente de las revistas para mujeres.

"A modo de conclusión", la autora nos plantea que el aparato disciplinario llamado feminidad, del que se ocuparon en los diferentes periodos históricos las revistas para mujeres, constituye una de las causas de la inequidad social entre los sexos en la medida en la que construyen modelos identitarios segregados que obstaculizan una efectiva inclusión. En este punto, y a modo de epílogo, Pura Sánchez no se resiste a una breve pero aguda e irónica disección de la revista "S Moda" que empieza a publicar El País en septiembre de 2011, para lamentarse sobre las importantes líneas de continuidad presentes en las revistas actuales, sólo que al servicio ahora de un consumismo feroz. Cosa 
que, tristemente, apoyan análisis como los de Méndez (1995) sobre revistas femeninas actuales.

En definitiva, la obra constituye un análisis lúcido, preciso, de lectura ágil y, por todos los aspectos aquí señalados, claramente recomendable.

\section{Referencias Bibliográficas:}

Campos Rubio, Arantza (1995) Charles Fourier: Pasión y Utopía. De la atracción pasional a la Política Sexual. Vizcaya: Universidad del País Vasco (Serie tesis doctorales).

Ehrenreich, Barbara y English, Deirdre [1979] (1990) Por tu propio bien. 150 años de consejos expertos a las mujeres. Madrid: Editorial Taurus.

Millet, Kate [1969] (1995) Política sexual. Barcelona: Editorial Cátedra Feminismos.

Méndez, Lourdes (1995) "Recetarios mágico-científicos al servicio de la estética de la delgadez. Cuerpos de mujeres, cuerpos de hombres". Actas do Seminario Anorexia, dieta, estética y crenzas. Santiago: Museo do Pobo Galego.

Molyneux, Maxine (1977) "Androcentrism in Marxist Anthropology". Critique of Anthropology, vol. 3 n 9-10.

Moreno, Amparo (1991) Pensar la historia a ras de piel. Barcelona: Ediciones de la Tempestad.

Scott, Joan (1990) "El género: una categoría útil para el análisis histórico". En Alemang y Nash (eds) Historia y género: las mujeres en la Europa moderna y contemporánea. Valencia: Editorial Alfons elMagnanim. 